\title{
Влияние поведенческих аспектов на структуру капитала российских публичных компаний
}

\author{
Гайфутдинова Н.С. ${ }^{13}$, Кокорева М.С. ${ }^{14}$
}

\begin{abstract}
В данной статье представлень результатьл эмпирического тестирования применимости поведенческих конщепций структуры капитала для объяснения формирования структуры капитала российскими компаниями. На выборке 50 крупных публичных компаний за 2003-2009 годы продемонстрирована несостоятельность теории отслеживания рынка в объяснении структуры капитала российских компаний. При этом результаты исследования не позволяют отвергнуть значимость модели информационных каскадов и гипотез, связанных с влиянием личных качеств менеджера, при выборе долговой нагрузки компании.
\end{abstract}

\section{$J E L: G 32$}

Ключевые слова: финансовый рычаг, структура капитала, теория информационных каскадов, теория отслеживания рынка, личные качества менеджера, поведенческие концุепцุии

\section{Введение}

Выявлению факторов и мотивов, влияющих на формирование структуры капитала в компаниях, посвящены многочисленные исследования, проведенные на данных как развитых, так и развивающихся рынков капитала. Однако окончательный вывод о применимости определенной теории к объяснению финансового рычага пока не сделан, что приводит к возникновению новых концепций, претендующих на возможность объяснения политики финансирования. Одной из альтернативных теорий является набор поведенческих концепций, которые приобрели популярность у исследователей в последние годы. Эмпирической проверке поведенческих концепций посвящены работы как на развитых (Malmeider, Tate, 2008; Hribar, Yang, 2010), так и на развивающихся рынках (Barros, Silveira, 2004). Однако на российском рынке подобные исследования пока не проводились. Данное исследование, проведенное на данных 50 российских компаний, снимает строгое ограничение о рациональности экономических агентов и подразумевает рассмотрение трех поведенческих подходов: теория отслеживания рынка, теория информационных каскадов и теория влияния личных качеств менеджера. Анализ проводится на основе динамической модели, учитывающей изменение во времени оптимального уровня финансового рычага, а также скорость подстройки к оптимальному значению.

\section{Обзор поведенческих моделей формирования структуры капитала}

Существует целый ряд работ, посвященных анализу формирования структуры капитала компании с точки зрения поведенческих эффектов. Исследователями предложено несколько теорий, описывающих процесс формирования структуры капитала, среди которых - теория отслеживания рынка, теория информационных каскадов и теория влияния личных качеств менеджера на структуру капитала компании.

\footnotetext{
${ }^{13}$ Выпускница магистерской программы «Стратегическое управление финансами фирмы» НИУ-Высшая школа экономики.

${ }^{14}$ Преподаватель кафедры экономики и финансов фирмы НИУ-Высшая школа экономики, сотрудник научноучебной лаборатории корпоративных финансов.
} 
В соответствии с теорией отслеживания рынка, компании выпускают акции в период высоких цен на рынке и производят выкуп в период низких цен. Рассматриваемая теория не исходит из предпосылки о неэффективности рынка, а предполагает, что менеджеры могут считать рынок неэффективным в определенные моменты времени.

Бэйкер и Вёглер (Baker, Wurgler, 2002), предложившие данную теорию, исследовали зависимость структуры капитала компаний, вышедших на IPO в период с 1968 до 1998 ггода, от их прошлой рыночной оценки. В качестве переменных, отвечающих за оценку компании, выступали три измерителя отношения market-to-book: максимум показателя с момента первичного выпуска акций до t-1 периода; прошлые значения market-to-book, взвешенные по долям внешнего финансирования; и значение показателя в предыдущем периоде. Наибольшую объясняющую силу продемонстрировал средневзвешенный показатель, что позволило авторам сформулировать следующую идею: менеджеры выпускают акции, если считают, что компании переоценена, а долг - если недооценена. Подтверждением данной теории может служить наблюдение Грэхэма и Харви (Graham, Harvey, 2001), которые с помощью опроса выявили, что 2/3 (из 392 опрошенных) финансовых директоров согласны со следующим утверждением: при выпуске акций «величина переоценки или недооценки является важным или очень важным фактором».

Ховакимиан (Hovakimian, 2004; Hovakimian, 2006) критиковал исследование Бэйкера и Вёглера (Baker, Wurgler, 2002), связывая значимость исторического среднего коэффициента market-to-book в регрессии не с отслеживанием рынка, а с возможностями роста, которые не полностью отражаются в текущем значении коэффициента. Лиу (Liu, 2005) и Кайан и Титман (Kayhan, Titman, 2007) также утверждали, что средневзвешенный показатель marketto-book отражает перспективы роста, что в большей степени соответствует динамической теории компромисса.

В подтверждение теории отслеживания рынка выступали Эллиотт и др. (Elliott et al., 2004; Elliott et al., 2008). Анализ данных по американским компаниям за 1971-2001 годы подтвердил, что компании, оцененные выше по сравнению с предыдущим годом, склонны большую часть своего дефицита финансировать с помощью собственного капитала. Результаты второго исследования подтвердили значимость влияния оценки компании рынком на принятие решений о выпуске акций.

Махаджан и Тартароглу (Mahajan, Tartaroglu, 2008) проверили выполнение теории отслеживания рынка на выборке компаний стран «большой семерки». Для компаний Франции, Великобритании, Канады и США подтвердилось значимое отрицательное влияние исторического market-to-book на долю долга. Однако проверка устойчивости результатов показала, что компании изменяли структуру капитала после выпуска акций так, что эффект от отслеживания рынка наблюдался менее пяти лет.

Чанг и соавторы (Chang et al., 2010) исследовали влияние отслеживания рынка на структуру капитала группы японских компаний, кейрецу. Кейрецу - японские конгломераты - представляют собой что-то среднее между полностью интегрированным конгломератом и отдельной компанией. Влияние эффекта следования рынку оказалось значимым, особенно для кейрецу по сравнению с отдельными компаниями.

В теории информационных каскадов утверждается, что менеджерам может быть выгодно не заниматься оценкой преимуществ и недостатков того или иного решения о финансировании, а скопировать действия менеджеров других компаний. Это связано с трудностью выбора оптимальной структуры капитала, требующего от менеджера серьезных усилий и высокой компетенции. Выбор финансового рычага в рамках данной теории определяется следующими способами: копирование структуры капитала компании - лидера отрасли; использование наиболее популярных среди компаний на текущий момент методов формирования структуры капитала; копирование медианного значения доли долга по отрасли.

Гипотезу о копировании применяемых моделей достаточно сложно проверить эмпирически, поэтому в подтверждение рассматриваемой теории приводятся аргументы, 
связанные со значимостью медианной или средней долговой нагрузки в отрасли. Гилсон (Gilson, 1997) утверждал, что рыночная конкуренция оказывает давление на компании в сторону копирования финансового рычага у других компаний в отрасли. Хулл (Hull, 1999) в своем исследовании выявил, что в период объявления об изменении финансового рычага доходность акций компаний, уходящих от среднеотраслевого показателя финансового рычага, значимо ниже доходности акций компаний, приближающихся к среднеотраслевому показателю. Таким образом, можно заключить, что инвесторы отрицательно относятся к уходу структуры капитала компании от среднеотраслевого уровня. Ховакимиан и др. (Hovakimian et al., 2001) выявили, что компании предпринимают активные действия для изменения структуры капитала в сторону среднеотраслевой.

Флэннери и Ранган (Flannery, Rangan, 2006) в исследовании изменения структуры капитала американских компаний из базы данных Compustat за период 1965-2001 годов, а также Фрэнк и Гоял (Frank, Goyal, 2009) в исследовании изменения структуры капитала американских торгуемых компаний за период 1950-2003 годов выявили значимое положительное влияние на финансовый рычаг медианного значения долговой нагрузки отрасли.

При исследовании формирования структуры капитала компании с точки зрения смещений в поведении (гипотезы влияния личных качеств менеджера на структуру капитала компании), обращают внимание на излишнюю уверенность и оптимизм менеджмента. Многие индивиды считают себя «лучше среднего» (Weinstein, 1980). Опрос, проведенный Грэхэмом и Харви (Graham, Harvey, 2001), подтвердил теорию оптимизма, выявив, что большинство менеджеров считают недооцененными акции их компаний. В настоящее время существует большое количество исследований, изучающих влияние самоуверенности менеджеров на принимаемые ими финансовые решения.

Малмейдер и Тейт (Malmeider, Tate, 2005a) определяли самонадеянность как слишком сильную подверженность генерального директора идиосинкратическому риску компании: исполнение опциона позже оптимальной даты, увеличение доли акций на руках. Авторы, объясняя зависимость вложений в инвестиционные проекты от достаточности собственных средств, предположили, что самонадеянные менеджеры переоценивают отдачу от инвестиционных проектов. Также авторы отметили, что такие менеджеры считают акции своей компании недооцененными рынком, поэтому они стараются не прибегать к выпуску акций для финансирования проектов. Малмейдер, Тейт и Ян (Malmeider, Tate, Yan, 2005) на той же выборке показали, что самонадеянные менеджеры для покрытия финансового дефицита используют больший объем долга по сравнению с другими менеджерами.

Оливер (Oliver, 2005) рассматривал влияние уверенности менеджеров на структуру капитала компании на выборке из 290 компаний за период с 1978 по 2004 год. В качестве прокси уверенности менеджера в благоприятной ситуации на рынке был выбран мичиганский индекс потребительского оптимизма (потребительских настроений), определяемый Мичиганским университетом на основе опроса населения о восприятии текущей и будущей экономической ситуации. Коэффициент при переменной, отвечающей за уверенность менеджеров, оказался положительным и значимым, что подтвердило предположение автора о том, что оптимистично настроенные менеджеры переоценивают вероятность успеха и недооценивают риск. Это приводит к большему использованию долгового финансирования. Однако данный измеритель оптимизма менеджеров не совсем корректен, таккак автором не принимается в расчет смещение в настрое менеджера, связанное с персонально его психологическими характеристиками.

Иной измеритель самонадеянности менеджеров, предложенный в работе Бен-Дэвида, Грэхэма и Харви (Ben-David, Graham, Harvey, 2007), соответствовал узости индивидуального распределения вероятности рыночной доходности. Рассматриваемая прокси-переменная была рассчитана на основе данных квартальных опросов, проводимых университетом Дьюка среди финансовых директоров и президентов компаний. Следует отметить, что, в отличие от подхода Малмейдера и Тейта (Malmeider, Tate, 2005; Malmeider, Tate, 2008), которые в своих 
работах рассматривали самонадеянность как ощущение менеджера себя «лучше других» (оптимизм), авторы определяли самонадеянность как слишком узкие доверительные интервалы при предсказании разных событий. Авторы исследовали взаимосвязь между мерой самонадеянности и политикой компании, включая объем капиталовложений, решения о слияниях и поглощениях, решения о финансировании и политику выплат. Было выявлено, что фирмы с самонадеянными СЕО отличаются более высокой долей долга.

Баррос и Силвейра (Barros, Silveira, 2004) протестировали влияние оптимизма и излишней самонадеянности менеджеров на выборке из 153 нефинансовых бразильских компаний, действовавших в 17 отраслях, акции которых торговались на фондовой бирже Сан Пауло с 1998 по 2003 год. В качестве прокси самоуверенности авторы использовали несколько переменных: дамми, говорящие о том, является менеджер предпринимателем (основатель компании или преемник) или наемным работником, и владение акциями управляемой компании. Для проверки гипотез авторы воспользовались динамической моделью структуры капитала. Переменная, отвечающая за личные качества менеджера, оказалась значимой, что не позволило отвергнуть гипотезу о положительном влиянии самонадеянности менеджера на уровень долга.

К работам, проверяющим применимость классических концепций к объяснению формирования структуры капитала российских компаний, относятся исследования ряда авторов (Ивашковская, Солнцева, 2009; Березинец и др., 2010; Delcoure, 2007). В перечисленных работах не сделан окончательный вывод о преимуществе одной из классических теорий над остальными. Шахина и Кокорева (Shahina, Kokoreva, 2010) исследовали применимость динамической теории компромисса к объяснению изменения структуры капитала российских компаний. Анализ модели подтвердил существование издержек изменения финансового рычага и наличие интервала оптимальных значений, при выходе из которого компании корректируют свой финансовый рычаг. В отличие от перечисленных исследований, в работе Иванова (Ivanov, 2010) наряду со стандартными факторами теорий компромисса и порядка финансирования рассматривалась прокси влияния самонадеянности менеджера. В качестве параметра самонадеянности была выбрана даммипеременная, равная 1 , если исполнительный директор компании одновременно являлся ее основным акционером. По результатам кросс-секционного регрессионного анализа компании, менеджеры которых обладали наибольшим пакетом акций, отличались более высоким уровнем долга, что подтверждает применимость теории влияния личных качеств менеджера на структуру капитала.

\section{Анализ влияния поведенческих аспектов на структуру капитала российских компаний}

$$
\text { Характеристика выборки }
$$

Для проведения данного исследования была собрана панель, содержащая данные по 50 крупным публичным российским компаниям из 11 отраслей, отвечающим следующим условиям:

- осуществляют нефинансовую деятельность;

- доступны все необходимые данные за весь период наблюдения (2003-2009);

- д доступна финансовая отчетность, составленная по стандартам US GAAP или МСФО;

- величина совокупных активов за все годы наблюдения не ниже 40 млн долларов и не превышает 300 млрд долларов.

Анализ переменных долговой нагрузки в динамике показал, что среднее значение финансового рычага (в данном исследовании доля процентного долга в совокупном капитале), рассчитанное на основе балансовых показателей, постепенно возрастает с течением времени с $18 \%$ в 2001 году до $26 \%$ в 2009-м. Это может свидетельствовать как о том, что использование заемного капитала становилось более популярным среди компаний, так и о том, что рынок долгового финансирования становился более доступным. Доля долга 
в общей стоимости компании, рассчитанная на основе рыночных показателей, значительно колеблется во времени, что объясняется большим влиянием различных экономических факторов на рыночную стоимость компании через цену ее акций. Например, можно заметить, что средний финансовый рычаг в 2008 году значительно снизился по сравнению с 2007-м, что обусловлено падением цен акций на рынке в связи с кризисом.

\section{Описание переменных и построение гипотез}

Финансовый рычаг в исследовании рассчитан как отношение долга к сумме заемного и собственного капиталов двумя способами: на основе балансовых (BFL) и на основе рыночных показателей собственного капитала (MFL). Решение об использовании двух методов расчета структуры капитала обусловлено несколькими причинами. Во-первых, в предшествующих исследованиях структуры капитала нет однозначного вывода о преимуществе одного способа расчета над другим. Также использование нескольких измерителей необходимо для получения сравнимых с другими работами результатов. И, наконец, сравнение результатов при использовании двух прокси-переменных предоставляет возможность дополнительной проверки результатов на устойчивость.

Согласно теории компромисса, налоговая ставка положительно влияет на финансовый рычаг компании, так как увеличивает налоговый щит (Huang, Song, 2006; Delcoure, 2007). Прокси данного фактора является эффективная налоговая ставка (tax), рассчитанная как отношение выплаченного налога на прибыль к прибыли до уплаты налогов. Исследователями также выделяется недолговой налоговый щит в виде амортизации, который, уменьшая налогооблагаемую базу, является субститутом налоговых выгод и отрицательно влияет на долю долга (Huang, Song, 2006; Delcoure, 2007). В данной работе в качестве переменной, отвечающей за недолговой налоговый щит, используется отношение амортизации к совокупным активам (DTA). Введение данных переменных в анализ позволило сформулировать следующие гипотезы.

Гипотеза 1. Финансовый рычаг положительно зависит от эффективной налоговой ставки.

Гипотеза 2. Недолговой налоговый щит отрицательно влияет на долю долга в совокупном капитале компании.

Исторически крупные компании сталкиваются с меньшим риском дефолта, следовательно, согласно компромиссной теории, должны иметь больший финансовый рычаг (Delcoure, 2007; Ивашковская, Макаров, 2010). Также крупным компаниям, имеющим сложившуюся репутацию, может быть легче привлекать недорогой заемный капитал, что должно приводить к более высокой долговой нагрузке. Однако некоторые исследователи (Frank, Goyal, 2009) не исключают возможности существования обратной зависимости, объясняя это тем, что у крупных зрелых компаний больше возможностей реинвестировать прибыль в финансирование различных проектов. В качестве детерминант размера компании в данном исследовании будут использованы такие показатели: Lnass - натуральный логарифм активов; Lns - натуральный логарифм продаж; Mature - срок жизни компании. Сформулирована следующая гипотеза относительно влияния размера компании на структуру капитала.

Гипотеза 3. Финансовый рычаг растет с ростом размеров компании.

Для более прибыльных фирм издержки финансовой неустойчивости ниже и выше возможности привлечения дополнительного долга, что свидетельствует в пользу положительной зависимости. Однако, согласно теории порядка финансирования, более прибыльные компании будут иметь больше внутренних средств и в меньшей степени полагаться на заемное финансирование (Delcoure, 2007; Ивашковская, Солнцева, 2007; Ivanov, 2010). В качестве показателя рентабельности активов (Prof) взято отношение прибыли до уплаты процентов и налогов к совокупным активам. Гипотеза о влиянии рентабельности активов на выбираемую долю долга в совокупном капитале следующая. 
Гипотеза 4. Существует обратная зависимость между уровнем рентабельности и финансовым рычагом компании.

Согласно теории компромисса, растущие компании будут иметь меньший финансовый рычаг, так как рост связан с увеличением издержек финансовой неустойчивости и усугублением агентских проблем, связанных с долговым финансированием (Huang, Song, 2006; Frank, Goyal, 2009). С точки зрения теории порядка финансирования, так как растущей компании требуется больше финансирования, при неизменной рентабельности она будет увеличивать долю долга (Ivashkovskaya, Solntseva, 2007; Ivanov, 2010). В качестве проксипеременной роста компании в данном исследовании будут использованы показатели:

- МТВ - отношение рыночной стоимости компании к ее балансовой стоимости;

- CapTA - отношение капитальных затрат к общим активам.

Гипотеза 5. Компании, обладающие возможностями роста, отличаются меньшим финансовым рычагом.

Высокая доля материальных активов в совокупных активах снижает ожидаемые издержки финансовой неустойчивости, так как здания и оборудования могут служить предметами залога или быть проданы (Delcoure, 2007; Ivashkovskaya, Solntseva, 2007; Frank, Goyal, 2009). Материальность активов компании в данном исследовании измеряется долей материальных внеоборотных активов в общих активах (FATA).

Гипотеза 6. Существует прямая зависимость между уровнем материальности активов и долей долга компании.

На издержки финансовой неустойчивости также влияет степень риска бизнеса, измеряемая стандартным отклонением прибыли до уплаты процентов и налогов (risk). C точки зрения компромиссной теории, зависимость финансового рычага от риска должна быть отрицательной (Booth et al. 2001; Delcoure, 2007). С другой стороны, компании с более волатильной прибылью могут чаще обращаться к внешнему рынку капитала, в том числе за долговым финансированием.

Гипотеза 7. Компании, отличающиеся высоким уровнем риска, имеют меньший финансовый рычаг.

В рассмотрение также будут включены переменные структуры собственности: доля акций в руках менеджера компании (M-own); доля акций в руках государства (Gov-own); доля акций в руках институциональных инвесторов (Inst-own).

Оптимальная структура собственности, согласно исследованиям Дженсена и Меклинга (Jensen, Meckling, 1976), минимизирует общие агентские издержки, тем самым оказывая влияние на необходимый фирме уровень долга. В работе Хуанга и Сонга (Huang, Song, 2006) была выявлена отрицательная взаимосвязь между долей акций в руках менеджмента и финансовым рычагом китайских компаний. Большие доли акций в руках государства или институциональных инвесторов, например, могут снизить агентские издержки и позволить компании сократить долю долга в стоимости (Ivanov, 2010).

Гипотеза 8. Доля акций в руках менеджмента снижает долговую нагрузку компаний.

Гипотеза 9. Финансовый рычаг положительно зависит от доли акций в руках государства.

Гипотеза 10. Для компаний с большей долей акций в руках институциональных инвесторов характерен более высокий уровень долга.

Для того чтобы учесть различия в формировании финансового рычага компаниями из разных отраслей, введены отраслевые дамми. Шоки макроэкономической ситуации призваны учесть дамми-переменные по годам наблюдения. Особый интерес представляют дамми-переменные по 2008 и 2009 годам, так как эти периоды включают воздействие кризиса, который мог повлиять на процесс формирования структуры капитала компаниями. 
Переменные, отвечающие за влияние поведенческих факторов

Согласно теории отслеживания рынка, текущий финансовый рычаг должен зависеть от прошлых оценок компании рынком (Elliott et al., 2008; Mahajan, Tartaroglu, 2008). В данной работе используется три альтернативных показателя прошлой оценки компании: показатель market-to-book прошлого периода $(\mathrm{MTB}(t-1))$, историческое среднее значение показателя (AvMTB) и средневзвешенное по доле внешнего финансирования (WAMTB). Последний показатель рассчитан следующим образом:

$$
\text { WAMTB }=\sum_{s=0}^{t-1} \frac{e_{s}+d_{s}}{\sum_{r=0}^{t-1}\left(e_{r}+d_{r}\right)}(1),
$$

где $e$ и $d$ обозначают чистые выпуски собственного и заемного капитала соответственно.

Гипотеза 11. Финансовый рычаг отрицательно зависит от переменных прошлой оценки компании.

Для проверки релевантности теории информационных каскадов были выбраны переменные среднеотраслевого и медианного показателя финансового рычага (Medfl). Предполагается, что если компания не руководствуется при принятии решений теорией информационных каскадов, то коэффициент при отвечающей за теорию переменной должен быть равен нулю, и доля долга должна полностью объясняться другими параметрами.

Гипотеза 12. Отраслевой медианный финансовый рычаг оказывает значимое положительное влияние на долю долга в стоимости компании.

По аналогии с исследованием Барроса и Силвейры (Barros, Silveira, 2007), рассматривающими влияние оптимизма и самонадеянности менеджера, в данном исследовании утверждается, что качества самонадеянности и оптимизма больше присущи менеджерам, 1) являющимся предпринимателями (они владеют бизнесом, которым управляют) или 2) владеющим большой долей акций компании, которой они управляют.

Рациональный экономический агент диверсифицирует свой портфель и должен предпочитать владеть акциями компаний отраслей, контрцикличных по отношению к той, в которой он работает. Поэтому владение менеджером большим пакетом акций своей компании может означать нерациональное поведение, которое в данном исследовании будет интерпретироваться как чрезмерная самоуверенность. В существующей литературе доля акций на руках менеджера рассматривается как сигнал инвесторам, но Баррос и Силвейра (Barros, Silveira, 2007) утверждают, что такие сигналы эпизодические, а владение менеджером акциями компании может быть достаточно долгосрочным. По мнению авторов, можно с меньшими затратами достичь тех же сигнальных целей, производя выкуп обращающихся на рынке акций. Для отражения данной специфики будет введена даммипеременная $O w n_{i t}$, равная 1, если доля акций в руках менеджера превышает медианное значение, и 0 , если это иначе.

Гипотеза 14. Компании, доля акций которых в руках у исполнительного директора или председателя совета директоров превышает медианное значение, имеют более высокий финансовый рычаг.

Эванс и Лейтон (Evans, Leighton, 1989), используя данные опросов населения за период 1968-1987 годов, на выборке из 150 тыс. мужчин показали, что предприниматели (2,67\% выборки) в большей степени верят в то, что их успешность зависит от их собственных действий. Регрессионный анализ, проведенный Бузениц и Барни (Busenitz, Barney, 1997), подтвердил, что предприниматели существенно более подвержены самонадеянности по сравнению с профессиональными менеджерами. Купер и др. (Cooper et al., 1988) по американским предпринимателям и Пинфолд (Pinfold, 2001) на выборке, состоящей из предпринимателей Новой Зеландии, показали, что предприниматели склонны переоценивать вероятность успеха своих проектов. Поэтому будем обозначать $O V E R_{i t}$ дамми-переменную, 
принимающую значение 1 , если руководитель компании $i$ в период $t$ является ее основателем или его преемником, и 0 , если это иначе. Также для проверки устойчивости результатов введем несколько альтернативных переменных: OVER1 - 1, если генеральный директор или председатель совета директоров является основателем компании, OVER2 - 1, только применительно к генеральному директору, OVER3 - 1, только применительно к председателю совета директоров.

Гипотеза 15. Доля долга выше у фирм, которыми руководит основатель или его преемник.

В данном исследовании роль прокси демографических характеристик менеджера играет возраст (Age). Альтернативной переменной возрасту является опыт работы менеджера (Exp), отражающий продолжительность его трудовой деятельности.

\section{Анализ модели формирования структуры капитала компании}

В данной работе целевой финансовый рычаг представляется функцией от различных переменных, отвечающих за внутренние характеристики компании и показатели внешней среды:

$L E V_{i t}^{*}=\beta^{T} x_{i t}+\varepsilon_{1 i t}(2)$

где $L E V_{i t}^{*}$ - целевое значение финансового рычага компании і в момент времени $t, x_{i t}-$ вектор детерминант структуры капитала, $\varepsilon_{1 i t}$ - случайная ошибка. С учетом существования транзакционных издержек процесс изменения финансового рычага будет иметь следующий вид:

$$
L E V_{i t}-L E V_{i t-1}=\lambda\left(L E V_{i t}^{*}-L E V_{i t-1}\right)+\varepsilon_{2 i t}(3)
$$

где $\varepsilon_{2 i t}-$ случайный шок с нулевым математическим ожиданием, $\lambda$ - коэффициент (скорость) подстройки $(0<\lambda<1)$. Чем ближе коэффициент $\lambda$ к единице, тем меньше транзакционные издержки и тем быстрее компания может изменять свой финансовый рычаг в соответствии с желаемым уровнем. Далее объединим уравнения (2) и (3):

$$
L E V_{i t}=(1-\lambda) L E V_{i t-1}+\lambda \beta^{T} x_{i t}+\lambda \varepsilon_{1 i t}+\varepsilon_{2 i t}(4)
$$

заменим (1- $\lambda$ ) на $\alpha, \lambda \varepsilon_{1 i t}+\varepsilon_{2 i t}$ на $\varepsilon_{i t}$, а $\lambda \beta^{T}$ на $\Theta^{T}$ :

$$
\begin{aligned}
& L E V_{i t}=\alpha L E V_{i t-1}+\Theta^{T} x_{i t}+\varepsilon_{i t}(5), \\
& \text { тогда } E\left[\varepsilon_{i t}\right]=0 .
\end{aligned}
$$

Если при анализе регрессии не учитывать переменную $L E V_{i t-1}$, как это делается в статических моделях, то из-за существования корреляции между ней и переменными хit можно получить некорректные оценки коэффициентов при детерминантах структуры капитала. Модель, представленная формулой 5, проанализирована с помощью двух методов моментов: Ареллано-Бонда и Бланделла-Бонда.

\section{Основные результаты исследования}

Результаты анализа влияния определенных в предыдущем разделе показателей на балансовый финансовый рычаг компаний за период 2003-2009 годов представлены в таблице 1. Проверка гипотезы об отсутствии детерминированного эффекта, а также тест Хаусмана показала, что наиболее предпочтительной для анализа данных моделью является модель с фиксированными эффектами. В регрессию также были добавлены даммипеременные, отвечающие за 2008 и 2009 годы. Переменные оказались незначимы, что свидетельствует о том, что наблюдения в период кризиса можно объединять со всеми наблюдениями в рамках рассматриваемой модели. 
Результаты анализа регрессии с фиксированными эффектами

\begin{tabular}{|c|c|c|c|}
\hline $\begin{array}{c}\text { Параметры } \\
\text { модели }\end{array}$ & $\begin{array}{c}\text { Зависимая переменная } \\
\text { - bfl, период- } \\
\text { 2003-2009 годы }\end{array}$ & $\begin{array}{c}\text { Зависимая } \\
\text { переменная - bfl } \\
\text { период - } \\
\text { 2005-2009 годы }\end{array}$ & $\begin{array}{c}\text { Зависимая } \\
\text { переменная - mfl } \\
\text { период - } \\
\text { 2003-2007 годы }\end{array}$ \\
\hline $\operatorname{tax}$ & $\begin{array}{l}-0,003 \\
(0,003)\end{array}$ & $\begin{array}{l}0,006^{*} \\
(0,003)\end{array}$ & $\begin{array}{l}0,003 \\
(0,07) \\
\end{array}$ \\
\hline$d t a$ & $\begin{array}{c}0,425 * * * \\
(0,116) \\
\end{array}$ & $\begin{array}{c}0,402 * * * \\
(0,136)\end{array}$ & $\begin{array}{l}-0,392 \\
(0,429) \\
\end{array}$ \\
\hline lnass & $\begin{array}{c}0,010 \\
(0,006)\end{array}$ & $\begin{array}{l}- \\
- \\
\end{array}$ & $\begin{array}{l}- \\
- \\
\end{array}$ \\
\hline $\ln s$ & - & $\begin{array}{c}0,001 \\
(0,013) \\
\end{array}$ & $\begin{array}{l}-0,009 \\
(0,011) \\
\end{array}$ \\
\hline prof & $\begin{array}{c}-0,295 * * * \\
(0,053)\end{array}$ & $\begin{array}{c}-0,251 * * * \\
(0,067)\end{array}$ & $\begin{array}{c}-0,503 * * * \\
(0,145)\end{array}$ \\
\hline$m t b$ & - & $\begin{array}{c}0,000 \\
(0,004)\end{array}$ & - \\
\hline capta & $\begin{array}{c}0,037 \\
(0,065)\end{array}$ & - & $\begin{array}{c}-0,098 \\
(0,200)\end{array}$ \\
\hline fata & $\begin{array}{l}-0,022 \\
(0,021)\end{array}$ & $\begin{array}{l}-0,015 \\
(0,022)\end{array}$ & $\begin{array}{l}0,177 * * \\
(0,089)\end{array}$ \\
\hline risk & $\begin{array}{l}-0,001 \\
(0,001)\end{array}$ & $\begin{array}{l}-0,002 \\
(0,002)\end{array}$ & $\begin{array}{l}-0,002 \\
(0,003)\end{array}$ \\
\hline wamtb & - & $\begin{array}{c}0,031 * * \\
(0,015)\end{array}$ & - \\
\hline m_own & $\begin{array}{c}-0,212 * * * \\
(0,043) \\
\end{array}$ & $\begin{array}{c}-0,156^{* *} \\
(0,065)\end{array}$ & $\begin{array}{l}-0,011 \\
(0,087) \\
\end{array}$ \\
\hline gov_own & $\begin{array}{c}0,070 \\
(0,048) \\
\end{array}$ & $\begin{array}{c}0,069 \\
(0,063)\end{array}$ & $\begin{array}{c}0,039 \\
(0,100)\end{array}$ \\
\hline inst_own & $\begin{array}{c}0,073 \\
(0,054)\end{array}$ & $\begin{array}{c}0,076 \\
(0,067) \\
\end{array}$ & $\begin{array}{c}0,226 \\
(0,108) \\
\end{array}$ \\
\hline medfl & $\begin{array}{c}0,513 * * * \\
(0,065)\end{array}$ & $\begin{array}{c}0,596 * * * \\
(0,089)\end{array}$ & $\begin{array}{c}0,460 * * * \\
(0,155)\end{array}$ \\
\hline over & $\begin{array}{l}0,064 * * \\
(0,027)\end{array}$ & $\begin{array}{l}0,075 * * \\
(0,035)\end{array}$ & $\begin{array}{c}0,219 * * * \\
(0,062)\end{array}$ \\
\hline own & $\begin{array}{c}0,009 \\
(0,010) \\
\end{array}$ & $\begin{array}{l}0,024^{*} \\
(0,013)\end{array}$ & $\begin{array}{l}-0,022 \\
(0,024)\end{array}$ \\
\hline own1 & $\begin{array}{l}- \\
-\end{array}$ & $\begin{array}{l}0,030^{*} \\
(0,015)\end{array}$ & $\begin{array}{l}-0,017 \\
(0,027)\end{array}$ \\
\hline age & $\begin{array}{c}0,048 \\
(0,060)\end{array}$ & $\begin{array}{l}0,171^{*} \\
(0,087)\end{array}$ & $\begin{array}{l}-0,089 \\
(0,136)\end{array}$ \\
\hline agel & $\begin{array}{l}- \\
-\end{array}$ & $\begin{array}{c}0,028 \\
(0,064)\end{array}$ & $\begin{array}{c}0,132 \\
(0,112)\end{array}$ \\
\hline _cons & $\begin{array}{c}0,007 \\
(0,056)\end{array}$ & $\begin{array}{l}-0,086 \\
(0,107)\end{array}$ & $\begin{array}{c}0,057 \\
(0,120)\end{array}$ \\
\hline $\begin{array}{l}\text { Количество: } \\
\text { наблюдений } \\
\text { групп }\end{array}$ & $\begin{array}{l}350 \\
50 \\
\end{array}$ & $\begin{array}{l}250 \\
50\end{array}$ & 250 \\
\hline
\end{tabular}


К внутренним характеристикам компании, демонстрирующим значимую прямую зависимость с уровнем долговой нагрузки, относятся логарифм продаж и отношение амортизации к общим активам, а также обратную зависимость - рентабельность компании. Прямая зависимость от натурального логарифма продаж соответствует гипотезе компромиссной теории о положительном влиянии размера компании на долю долга. Обратная зависимость доли долга от рентабельности активов соответствует теории порядка финансирования, так как при наличии у компании достаточных внутренних источников она будет использовать их для финансирования проектов, прибегая к выпуску долга с меньшей вероятностью. Полученный результат соответствует выводам исследований, проведенных по российским компаниям (Ivashkovskaya, Solntseva, 2007; Ивашковская, Солнцева, 2009). Прямая зависимость от отношения амортизации к совокупным активам может быть объяснена с двух точек зрения. Во-первых, зависимой переменной является балансовый финансовый рычаг, т.е. величина совокупных активов компании, стоящая в знаменателе показателей, уменьшает как зависимую, так и объясняющую переменную. Также начисленная амортизация уменьшает прибыль компании, следовательно, положительно влияет на финансовый рычаг через воздействие на рентабельность активов. Прямой зависимостью характеризуется медианный показатель финансового рычага. Данный эффект может быть объяснен с точки зрения теории информационных каскадов, утверждающей, что управляющим компанией выгодно копировать структуру капитала у конкурентов. Однако следует помнить, что данный показатель может агрегировать все неучтенные в модели переменные, отвечающие за характерные черты отдельных отраслей. Детерминанты самонадеянности менеджера, как и предполагалось, отличаются прямой зависимостью с показателем структуры капитала. Переменная $O V E R_{i t}$ значима на 5\%-ном уровне значимости, что подтверждает гипотезу о прямой зависимости между самонадеянностью менеджера и финансовым рычагом компании. Переменные own и ownl также характеризуются прямой зависимостью с долей долга, однако коэффициент при own незначим, а при ownl - значим на 10\%-ном уровне значимости. Из чего можно заключить, что превышение доли акций в руках председателя совета директоров над медианным значением оказывает большее влияние на финансовый рычаг по сравнению с долей владения акциями исполнительным директором. Данный эффект может свидетельствовать о следующем: самонадеянные основатели компаний предпочитают занимать пост председателя совета директоров или же для компаний из рассматриваемой выборки характерен высокий контроль действий генерального директора со стороны совета директоров, вследствие чего самонадеянность председателя совета директоров в большей степени влияет на структуру капитала компании.

В связи с использованием в качестве детерминант прошлой оценки компании рынком исторических показателей market-to-book, для анализа применимости теории отслеживания рынка к объяснению выбора компанией структуры капитала из периода наблюдения были исключены 2003 и 2004 годы. Как и в предыдущем случае, по критериям коэффициента детерминации и теста Хаусмана была выбрана модель с фиксированными эффектами (таблица 1). Знаки и уровень значимости коэффициентов при переменных, отвечающих за внутренние характеристика компании и за поведенческие теории, совпадают со знаками, полученными по выборке за 2003-2009 годы, что свидетельствует об их устойчивости. Влияние показателя теории отслеживания рынка - исторического среднего значения marketto-book - оказалось, как и предполагалось, отрицательным, но незначимым. Влияние предыдущего значения market-to-book также оказалось незначимым. Коэффициент при отношении рыночной стоимости к балансовой, взвешенной по доле финансирования, оказался положительным и значимым на 5\%-ном уровне значимости. Данное наблюдение можно объяснить с позиции Ховакимиан (Hovakimian, 2006), который связывал средневзвешенный по доле внешнего финансирования показатель с постепенно меняющимися возможностями роста, которые не полностью отражаются его текущим значением. Это также подтверждается тем фактом, что влияние на финансовый рычаг используемых для отражения перспектив роста компании переменных (mtb, capta) 
незначимо. Таким образом, следование российскими компаниями теории отслеживания рынка не подтверждается.

В рамках анализа модели с рыночным финансовым рычагом в качестве зависимой переменной помимо уже рассмотренных зависимостей выявлена значимая прямая зависимость финансового рычага от уровня материальности компании, что соответствует выводам компромиссной теории. Также была выявлена значимая прямая зависимость доли долга от доли акций в руках институциональных инвесторов. Даная зависимость могла появиться вследствие выбора институциональными инвесторами крупных, наименее рисковых компаний, которые, согласно теории и полученным эмпирическим выводам, имеют более высокий финансовый рычаг. Следует отметить, что для анализируемой выборки влияние переменной самонадеянности менеджера также оказалось значимым и положительным, что подтверждает предыдущие выводы.

Анализ динамической регрессии с балансовым финансовым рычагом в качестве зависимой переменной проводился на основе метода Ареллано-Бонда и метода БланделлаБонда. Согласно тесту Саргана, гипотеза о валидности инструментов не отвергается. По результатам теста на автокорреляцию ошибки в модели Ареллано-Бонда автокоррелированы, что говорит о смещении оценок стандартных отклонений оценок коэффициентов и невозможности адекватной интерпретации данных коэффициентов. Поэтому в качестве итоговой модели выбрана модель Бланделла-Бонда (таблица 2). Согласно анализу данной модели, значимым влиянием на финансовый рычаг отличаются: финансовый рычаг предыдущего периода, недолговой налоговый щит, уровень прибыльности компании, уровень риска, медианный по отрасли финансовый рычаг, дамми статуса исполнительного директора или председателя совета директоров и доля акций компании, принадлежащая председателю совета директоров. Знаки и значимость большинства из перечисленных переменных соответствуют результатам анализа статической модели и прокомментированы в предыдущем параграфе. Из неосвещенных переменных положительное влияние на долю долга оказывает лаговая переменная. Значимость данной переменной свидетельствует о существовании скорости подстройки. Отрицательное влияние уровня риска на финансовый рычаг соответствует предсказаниям теории компромисса. На основе рассматриваемой модели можно заключить, что подтверждаются гипотезы 4, 7, 12, 13. Отвергается гипотеза 2.

Таблица 2

Результаты анализа динамических регрессий обобщенным методом моментов БланделлаБонда

\begin{tabular}{|c|c|c|}
\hline $\begin{array}{c}\text { Параметры } \\
\text { модели }\end{array}$ & $\begin{array}{c}\text { Зависимая переменная } \\
- \text { bfl } \\
\text { период наблюдения - } \\
\text { 2003-2009 годы }\end{array}$ & $\begin{array}{c}\text { Зависимая } \\
\text { переменная -mfl } \\
\text { период наблюдения - } \\
\text { 2005-2009 годы }\end{array}$ \\
\hline L.bfl & $\begin{array}{c}0,418 * * * \\
(0,102)\end{array}$ & $\begin{array}{l}- \\
- \\
\end{array}$ \\
\hline L.mfl & $\begin{array}{l}- \\
-\end{array}$ & $\begin{array}{c}0,469 * * * \\
(0,108)\end{array}$ \\
\hline $\operatorname{tax}$ & $\begin{array}{l}-0,004 \\
(0,003) \\
\end{array}$ & $\begin{array}{l}-0,001 \\
(0,002)\end{array}$ \\
\hline$d t a$ & $\begin{array}{c}0,482 * * * \\
(0,113)\end{array}$ & $\begin{array}{c}-0,741 * * * \\
(0,233) \\
\end{array}$ \\
\hline lnass & - & $\begin{array}{c}-0,004 \\
(0,008) \\
\end{array}$ \\
\hline $\ln s$ & $\begin{array}{c}-0,002 \\
(0,007)\end{array}$ & - \\
\hline
\end{tabular}




\begin{tabular}{|c|c|c|}
\hline prof & $\begin{array}{c}-0,094^{*} \\
(0,057)\end{array}$ & $\begin{array}{c}-0,296^{* *} \\
(0,119)\end{array}$ \\
\hline capta & $\begin{array}{c}0,067 \\
(0,062)\end{array}$ & $\begin{array}{l}-0,148 \\
(0,326)\end{array}$ \\
\hline fata & $\begin{array}{l}-0,001 \\
(0,021)\end{array}$ & $\begin{array}{l}0,102^{*} \\
(0,062)\end{array}$ \\
\hline risk & $\begin{array}{c}-0,003^{* *} \\
(0,001) \\
\end{array}$ & $\begin{array}{l}-0,005^{*} \\
(0,003)\end{array}$ \\
\hline m_own & $\begin{array}{c}0,016 \\
(0,060)\end{array}$ & $\begin{array}{c}0,081 \\
(0,135)\end{array}$ \\
\hline gov_own & $\begin{array}{l}-0,029 \\
(0,064)\end{array}$ & $\begin{array}{l}-0,047 \\
(0,104)\end{array}$ \\
\hline inst_own & $\begin{array}{c}0,088 \\
(0,056)\end{array}$ & $\begin{array}{c}0,115 \\
(0,115)\end{array}$ \\
\hline medfl & $\begin{array}{c}0,527 * * * \\
(0,076)\end{array}$ & $\begin{array}{c}0,706^{* * *} \\
(0,194)\end{array}$ \\
\hline over & $\begin{array}{l}0,056^{*} \\
(0,030)\end{array}$ & $\begin{array}{c}0,243^{* * *} \\
(0,055)\end{array}$ \\
\hline own & $\begin{array}{c}0,013 \\
(0,012)\end{array}$ & $\begin{array}{c}0,009 \\
(0,020)\end{array}$ \\
\hline own1 & $\begin{array}{l}0,025^{*} \\
(0,015)\end{array}$ & $\begin{array}{l}0,070^{*} \\
(0,031)\end{array}$ \\
\hline age & $\begin{array}{c}0,044 \\
(0,071)\end{array}$ & $\begin{array}{c}0,025 \\
(0,139)\end{array}$ \\
\hline age1 & $\begin{array}{c}0,015 \\
(0,057)\end{array}$ & $\begin{array}{c}0,050 \\
(0,107)\end{array}$ \\
\hline $\begin{array}{l}\text { Количество } \\
\text { наблюдений } \\
\text { Количество }\end{array}$ & 300 & 200 \\
\hline
\end{tabular}

В таблице 2 также представлены результаты анализа влияния выбранных переменных на рыночный финансовый рычаг за период, не включающий кризис. Модель БланделлаБонда, как и в предыдущем случае, выбрана по критерию отсутствия автокорреляции. Вследствие того что тест Саргана о валидности инструментов был отвергнут, были рассчитаны устойчивые оценки стандартных отклонений оценок коэффициентов. Результаты анализа подтверждают результаты, полученные с зависимым балансовым финансовым рычагом. В отличие от модели объяснения финансового рычага, рассчитанного на основе балансовых показателей, и рассмотренных статических моделей, в данной модификации влияние недолгового налогового щита отрицательно и согласуется с выводами теории компромисса. На основе данной модели подтверждаются гипотезы 2, 4, 6, 7, 12, 13 и 14. Как и предыдущая, данная модель подтверждает гипотезы, касающиеся влияния поведенческих эффектов, что свидетельствует об устойчивости их влияния на финансовый рычаг компаний.

\section{Заключение}

Существующие подходы к определению структуры капитала предполагают, что все участники финансового рынка действуют рационально, но менеджерам присущи отклонения в поведении, которые оказывают существенное влияние на принимаемые ими решения. В данной работе с помощью различных эмпирических методов был проведен анализ применимости существующих поведенческих теорий для объяснения формирования 
структуры капитала российскими публичными компаниями. Эмпирический анализ данных не подтвердил состоятельность теории отслеживания рынка в объяснении структуры капитала российских компаний. Для проверки релевантности теории информационных каскадов в модель была включена переменная медианного по отрасли показателя структуры капитала. Во всех модификациях модели коэффициент при рассматриваемой переменной был положительным и значимым на 1\%-ном уровне значимости. Однако следует отметить, что из положительного значимого влияния переменной невозможно сделать точный вывод о применимости рассматриваемой теории, так как медианный по отрасли финансовый рычаг может отражать влияние всех неучтенных характеристик отрасли, в которой действует компания. По результатам эмпирического анализ гипотезы, связанные с влиянием личных качеств менеджера, подтвердились. Была выявлена значимая положительная зависимость доли долга от статуса исполнительного директора. Данная зависимость была выявлена во всех модификациях модели и носила устойчивый характер при проверке моделей на верную спецификацию, валидность инструментов и автокорреляцию ошибки. Влияние долей акций в руках исполнительного директора и председателя совета директоров оказалось значимо не во всех моделях. Однако следует упомянуть, что в ежеквартальных отчетах эмитента по многим компаниям в качестве владельцев пакетов акций часто указаны номинальные держатели. Таким образом, показатели владения акциями могут быть не совсем корректными прокси.

В рамках дальнейшего развития исследования может быть затронута проблема эндогенности структуры собственности при объяснении формирования структуры капитала, а также рассмотрено влияние поведенческих эффектов на разные группы фирм, разделенные, например, по критерию размера или типа владения.

\section{Список литературы}

1. Березинец И.В., Размочаев А.В., Волков Д.Л. Финансовые решения российских компаний: результаты эмпирического анализа // Вестник Санкт-Петербургского университета. Сер. 8. 2010. Вып. 1. С. 107-130.

2. Ивашковская И. Макаров П. Действуют ли классические концепции выбора структуры капитала на развивающихся рынках? Эмпирический анализ компаний Восточной и Центральной Европы // Корпоративные финансы. 2010. № 15. С. 47-62.

3. Ивашковская И. Солнцева М. Детерминанты стратегических решений о финансировании крупных компаний на развивающихся рынках капитала: пример России, Бразилии и Китая // Российский журнал менеджмента. 2009. № 1. Т. 7. С. 2542.

4. Масленникова М. Степанова А. Влияние структуры собственности на эффективность деятельности на примере российских и бразильских компаний // Корпоративные финансы. 2010. № 15. С. 35-46.

5. Baker, M. Wurgler, J. (2002), Market timing and capital structure, Journal of Finance, 57 (2002) 1-32.

6. Barros, L. Silveira, A. (2007), Overconfidence, managerial optimism and the determinants of capital structure, Working Paper7.

7. Ben-David, I. Graham, J. Harvey, C. (2007), Managerial Overconfidence and Corporate Policies, NBER Working Paper, November.

8. Blundell, R. Bond, S. Windmeijer, F. Estimation in Dynamic Panel Data Models: Improving on the Performance of the Standard GMM Estimator, the Institute for Fiscal Studies, WP $00 / 12$.

9. Booth, L. Aivazian, V. Demirguc-Kant, A. Maksimovic, V. (2001), Capital structures in developing countries, Journal of Finance, 1(56) (2001) 87-130.

10. Busenitz, L. Barney, J. (1997), Differences between Entrepreneurs and Managers in Large Organizations: Biases and Heuristics in Strategic Decision-making, Journal of Business Venturing, 12 (1997) 9-30. 
11. Chang, X. Hilary, G. Shih, H. Tam, L. (2010), Conglomerate structure and capital market timing, Working Paper.

12. Cooper, A. Woo, C. Dunkelberg, W. (1988), Entrepreneurs' perceived chances for success, Journal of Business Venturing, 3 (1988) 97-108.

13. Delcoure, N. (2007), The Determinants of Capital Structure in Transitional Economies, International Review of Economics and Finance, 16 (2007) 400-415.

14. Elliott, W. Koeter-Kant, J. Warr, R. (2004), Futher evidence on the financing deficit: The impact of market timing, Working Paper.

15. Elliott, W. Koeter-Kant, J. Warr, R. (2008), Market timing and the debt-equity choice, Journal of Financial Intermediation, 17 (2008) 175-197.

16. Evans, D. Leighton, L. (1989), Some Empirical Aspects of Entrepreneurship, American Economic Review, 79 (1989) 519-535.

17. Frank, M.Z. Goyal, V.K. (2009), Capital Structure Decisions, Financial Management, 1(38) (2009) 1-37.

18. Gilson, S.C. (1997), Transactions Costs and Capital Structure Choice: Evidence from Financially Distressed Firms, Journal of Finance, 52 (1997) 161-196.

19. Graham, J. Harvey, C. (2001), The theory and practice of corporate finance: evidence from the field, Journal of Financial Economics, 60 (2001) 187-243.

20. Hovakimian, A. Opler, T. Titman, S. (2001), The Debt-Equity Choice, Journal of Financial and Quantitative Analysis, 36 (2001) 1-24.

21. Hovakimian, A. (2004), The role of target leverage in security issues and repurchases, Journal of Business, 77 (2004).

22. Hovakimian, A. (2006), Are Observed Capital Structures Determined by Equity Market Timing? Journal of Financial and Quantitative Analysis, 41 (2006) 221-243.

23. Hribar, P. Yang, H. (2010), Does CEO Overconfidence Affect Management Forecasting and Subsequent Earnings Management? Working Paper.

24. Huang, G. Song, F. M. (2006), The Determinants of Capital Structure: Evidence from China// China Economic Review, 17 (2006) 14-36.

25. Hull, R.M. (1999), Leverage Ratios, Industry Norms, and Stock Price Reaction: An Empirical Investigation of Stock-for-Debt Transactions, Financial Management, 28 (1999) $32-45$.

26. Ivanov, I. (2010), Capital structure determinants of Russian public companies. Journal of Corporate Finance, 13 (2010) 5-38.

27. Ivashkovskaya, I. Stepanova, A. (2010), Does Strategic Corporate Performance Depend on Corporate Financial Architecture? Empirical Study of European, Russian and Other Emerging Market's Firms, Journal of Management and Governance, 2 (2010) 1-14.

28. Kayhan, A. Titman, S. Firms' histories and their capital structures, Journal of Financial Economics, 83 (2007) 1-32.

29. Liu, L.X. (2005), Do firms have target leverage ratios? Evidence from historical market-tobook and past returns, University of Rochester Working Paper.

30. Mahajan, A. Tartaroglu, S. Equity Market Timing and Capital Structure: International Evidence, Journal of Banking \& Finance, 32 (2008) 754-766.

31. Malmeidier, U. Tate, G. (2005a), CEO Overconfidence and Corporate Investment, Journal of Finance, 60 (2005a) 2661-2700.

32. Malmeidier, U. Tate, G. (2005b), Does overconfidence affect corporate investment? CEO overconfidence measures revisited, European Financial Management, 11 (2005b) 649-659.

33. Malmendier, U. Tate, G. (2008), Who makes acquisitions? CEO overconfidence and the market's reaction, Journal of Financial Economics, 89 (2008) 20-43.

34. Malmendier, U. Tate, G. Yan, J. (2005), Corporate Financial Policies with Overconfident Managers, Working Paper.

35. Modigliani, F. Miller, M. The Cost of Capital, Corporation Finance and the Theory of Investment, American Economic Review, 48 (1958) 261-297. 
36. Modigliani, F. Miller, M. Corporate Income Taxes and the Cost of Capital: A Correction, American Economic Association, 3(53) (1963) 433-443.

37. Oliver, B. (2005), The Impact of Management Confidence on Capital Structure, Working Paper.

38. Pinfold, J. (2001), The expectations of new business founders: the New Zealand case, Journal of Small Business Management, 39 (2001) 279-285.

39. Shahina, N. Kokoreva, M. (2010), Empirical Testing of Dynamic Capital Structure Choice: Case of Russian Companies, Journal of Corporate Finance, 16 (2010) 31-40.

40. Weinstein, N. (1980), Unrealistic optimism about future life events, Journal of Personality and Social Psychology, 39 (1980) 806-820. 